\title{
The impact of agricultural activities on gas effect generation
}

\author{
Lavinia Popescu $^{1}$, Adela Sorinela Safta ${ }^{1}$ \\ ${ }^{I}$ The Bucharest University of Economic, Romania \\ E-mail: saftaadela19@stud.ase.ro
}

\begin{abstract}
The paper provides an overview of the agricultural economy regarding the development of agriculture and rural space. Prioritizing an action behavior in terms of vulnerabilities favors the orientation of agriculture through more environmentally friendly methods. The emphasis is on the possibility of facilitating the implementation of modernized production models in the agricultural sector, while adopting a behavior that favors the orientation of agriculture through more environmentally friendly methods. Promoting an agricultural model capable of ensuring its own sustainability implies the existence of a set of common values and rules in which to buy as many producers as possible, with a common objective, namely to reduce greenhouse emissions and promote a production model responsible for the environment. During the research we tried to highlight issues that, in our opinion, are important for the development of the agricultural sector as part of the economy. An important role is played by the implementation of the best practices in the correct management of the land and the promotion of the models of organic production that can significantly contribute to the increase of the carbon absorption in the soil and, at the same time, to the indication of the possible improvements of its performance.
\end{abstract}

Keywords: soil, environmental, carbon emissions, performance

\section{Introduction}

The rural society, at the level of the whole country, is currently undergoing a transition process, a direct result of the socio-economic changes produced by the transition to the market economy. Thus, the rural environment knows a dynamic reality, constantly evolving and confronting the urban environment. The concept of "rural" defines the whole of the space in which villages or communes are located, the relations of interdependence created between them, the resident human communities and the related geographical, demographic, ecological and socio-cultural particularities. The rural area is characterized by a low density of housing and population, economic activities mainly carried out in the primary sector (agriculture, forestry, animal husbandry), a strong sense of belonging of the inhabitants to the community and the space of residence, a village cultural identity.

Research and development is important for all academic fields and industries. From this perspective, agriculture as a field is not an exception, having a special relevance starting from tradition. The article points out that in scientific research, interdependence should be analyzed with other areas that have the role of improving the quality of research through innovation, so that the agricultural sector's research is complemented by various forms of academic knowledge that have proved to be vital, such as quality soil. Approaching innovations in terms of methodologies applied in other sciences such as management, mathematics, even correlating soil degradation processes, determining the main pollutants, monitoring 
and controlling the soil, monitoring the soil quality status are relevant for agriculture. First, the dissemination of information from various fields can make information more efficient. The proper classification of these information resources may entail prioritizing the use of new information on detailed topics, such as performance in land / soil use, that is, which production would lead to higher long-term profit.

\section{Literature review}

Agriculture can significantly contribute to achieving the objectives of reducing the negative effects generated by climate change, not only from the perspective of ensuring the conservation of carbon reservoirs, which are still present in the soil, or by extending their size and favoring humus formation, as indicated. and in some specialized studies (Zhang et al., 2017; Adewale et al., 2019; Huang et al., 2019), but especially by reducing the energy consumption required in agricultural production and the supply of biomass needed for renewable energy production., much more environmentally friendly. As it is argued in (CES, 2008), agriculture is not only a victim of climate change, but itself contributes to the emission of greenhouse gases. At the same time, (Agovino et al., 2019), they argue that agriculture and climate change are characterized by a complex cause-and-effect relationship and the agricultural sector generates significant amounts of climate-affecting gas emissions.

The change of agricultural paradigms, and the orientation of agriculture towards more environmentally responsible practices, is a current trend, with broad support within the Common Agricultural Policy (CAP). The introduction in 2013 of payments for greening, within the CAP, aimed both to improve the environmental and climate performance of this sector policy, and to provide the premises of a reward mechanism for public goods produced by farmers. Thus, as noted in (Westhoek et al., 2014; Andrei et al., 2015), the payment for greening promoted under the CAP achieves two distinct fundamental objectives: improving the ecological and environmental performance of agriculture, on the one hand. , and supporting the income of farmers, on the other.

A proper land management analysis can significantly contribute to the increase of soil carbon uptake and also indicate any potential improvements in their performance. As stated by (Yadav \& Wang, 2017), agricultural land is a major source of atmospheric greenhouse gas (GHG) emissions and contributes majorly to global climate change, in the context of $20 \%$ of total GHGs. is issued from agricultural land.

Starting from these considerations we will analyze influences on soil carbon storage and the importance of nitrates.

From this perspective, the promotion of an agricultural model capable of ensuring its own sustainability implies the existence of a set of common values and rules to which to purchase as many producers as possible, with a common objective, namely to reduce emissions effectively greenhouse and promoting an environmentally responsible production model. Although some significant progress has been made in promoting environmentally responsible agriculture, and conditions have been created for the transition to an efficient agrarian economy from the point of view of the use of available resources, the issue of greenhouse gas emissions from numerous agriculture has arisen. academic debates. The transition to a low carbon economy, more environmentally responsible, in the national agricultural sector can contribute, both to the significant increase of food security, but also to the optimization of the agricultural production structures, which will thus conform much easy to environmental requirements.

The need to reduce carbon emissions and develop their level of absorption at the farm level acts, as noted in some specialized studies (Ramírez et al., 2019; Aznar-Sánchez et al., 2019) as an incentive in promoting the use of biomass as a raw material in the production of different categories of organic products, for the decarbonisation of agricultural production as a whole and the consolidation of carbon reservoirs. In this context, the assessment of the costs and the economic-financial impact of the sequestration of $4 \%$ / year of the carbon dioxide at the farm level is an important step in analyzing the 
Thoth Publishing House

possibilities of decarbonisation of agriculture and the promotion of the principles of bioeconomy in agriculture.

The EU has set targets to reduce its greenhouse gas (GHG) emissions by at least $40 \%$ by 2030 , compared to 1990. It is estimated that by 2030 they will be $30 \%$ below the 1990 level. (based on the Member State forecasts for March 2017).

It is expected that in the medium and long term climate change will increasingly affect the agricultural sector, the constant increase in annual temperature, according to projections for Europe, varies between 0.5 degrees $\mathrm{C}$ and 1.5 degrees $\mathrm{C}$ by 2029 depending on from the global scenario.

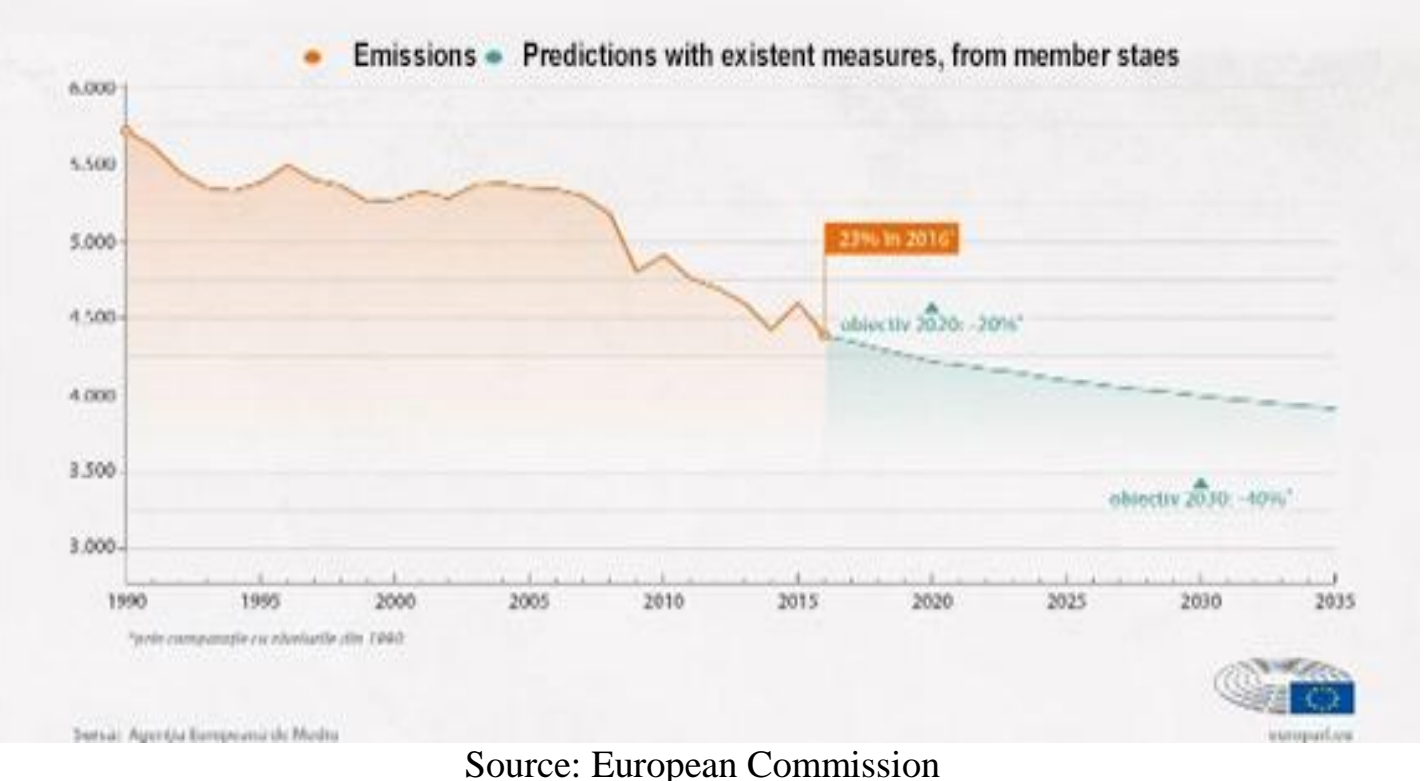

Figure 1. Greenhouse gas emissions: trends, emissions, forecasts and targets for the EU (millions of tons $\mathrm{CO} 2$ )

\subsection{Greenhouse gas emissions tend to emit forecasts and targets for $E U$}

Agriculture, in particular intensive farming, exerts a negative impact on the environment and climate. Greening - a direct payment rewarding farmers for farming practices beneficial for soil quality, carbon sequestration and biodiversity - was introduced in 2015, as a means to enhance the environmental and climate performance of the EU's Common Agricultural Policy. We found that greening, as currently implemented, is unlikely to meet this objective, mainly due the low level of requirements, which largely reflect the normal farming practice. We estimate that greening has led to a change in farming practice on only around $5 \%$ of all EU farmland post 2020.

In the literature, several studies have tried to make an assessment of the costs of reducing GHG emissions for different economies, as well as various estimates made in recent years, which vary significantly for example for the entire planet from $1 \%$ of GDP, and for the EU from $0.6 \%$ only for energy production, to $2.1 \%$ of GDP, and for the US from $1 \%$ to $4 \%$ of GDP, depending on the type of measures and the inclusion of financial costs, as well as of other economic assumptions.

The reduction of agricultural emissions at EU-28 level is mainly due to a decrease in the number of animals, improvements in the level of good agricultural practices, the lower use of nitrogen-based fertilizers, as well as a better management of natural soil fertilizers, the importance of the zootechnical sector and agricultural practices regarding biomass. 
Thoth Publishing House

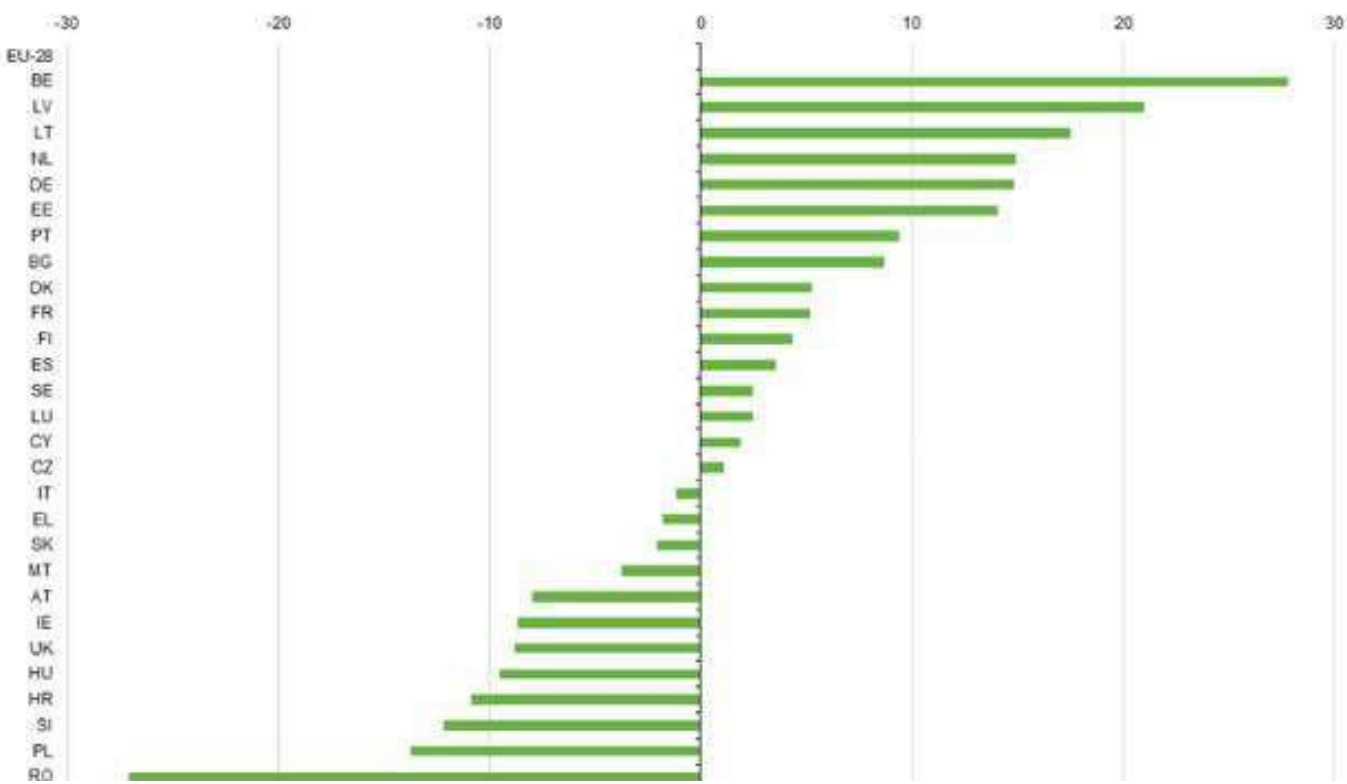

Source: European Environment Agency

Figure 2. Modification of aggregate methane and nitrogen oxide emissions from agriculture (1990-2011)

For Romania, the main sources of greenhouse gases are nitrous oxide (N2O) based on soil nitrification and management of natural fertilizers, the resulting methane $(\mathrm{CH} 4)$ from enteric fermentation of herbivores, mainly cattle, and carbon dioxide (CO2) from from the energy / fuel used by buildings and machines. $50 \%$ of agricultural emissions are nitrogen oxide, followed by $45 \%$ methane, while only $5 \%$ of emissions are based on carbon dioxide.

Carbon sequestration contributes to the overall goal of lowering greenhouse gas concentrations in the atmosphere. The incorporation of the vegetal mass in the soil on the agricultural lands where green crops are established, contributes to carbon sequestration. But the result of this objective will be quantified by monitoring the surfaces on which green crops were established, as well as by quantifying the amount of plant biomass resulting from afforestation.

\subsection{Low carbon agriculture sector analysis}

Romanian farmers rely heavily on organic fertilizers, most of them coming from individual farms. Inadequate management of animal waste, especially in subsistence agriculture, together with the rare wastewater treatment facilities in rural areas contributes to this environmental impact.

The process of land abandonment has accelerated in Romania in the past years, resulting in the loss of biodiversity. Uncultivated land has increased by $50 \%$ since 2005 , and, at 952,000 ha, constitutes $7 \%$ of the total agricultural area of the country (2010). The abandonment of agricultural land has far-reaching effects on ecosystem services, such as increased carbon storage, lower soil erosion, better water quality, and loss of traditional cultural landscapes. These effects often result in a decline in biodiversity. Also, the lack of appropriate knowledge, as a result of problems with the farm consulting system, results in often inadequate agricultural practices, with a negative influence on biodiversity. Even the relatively low yields of feed production, largely determined by improper pasture management, lead to erosion and loss of biodiversity.

In the context of climate change, there is a need for a new activity in the agricultural field, which means using natural resources and good practice models to provide observation systems, information 
Thoth Publishing House

management understanding, modeling and analysis of environmental phenomena for evaluation, exploitation and management, natural resources (water soil, climate).

Specific, local environmental and climate-related needs can be appropriately addressed through stronger programmed action regarding agriculture that is based on the achievement of performance targets and funding reflecting an assessment of the average costs incurred and income foregone in relation to actions and practices going beyond the environmental baseline.

Romanian agriculture has low productivity, and rural areas are disproportionally poor. An important factor in low productivity is the large share of small agricultural holdings. The sector needs to consider adaptation to a changing and less favorable climate going forward, as well as mitigate Gree House Gas (GHG) emissions.

The figure. 3 below shows the greenhouse gas emissions from EU28 in 2017, broken down by main source sectors. Energy accounts for $80.7 \%$ of greenhouse gas emissions in the EU28 in 2017, and transport accounts for about one third. Greenhouse gas emissions from agriculture contribute $8.72 \%$, industrial processes and product use by $7.82 \%$, and waste management by $2.75 \%$.

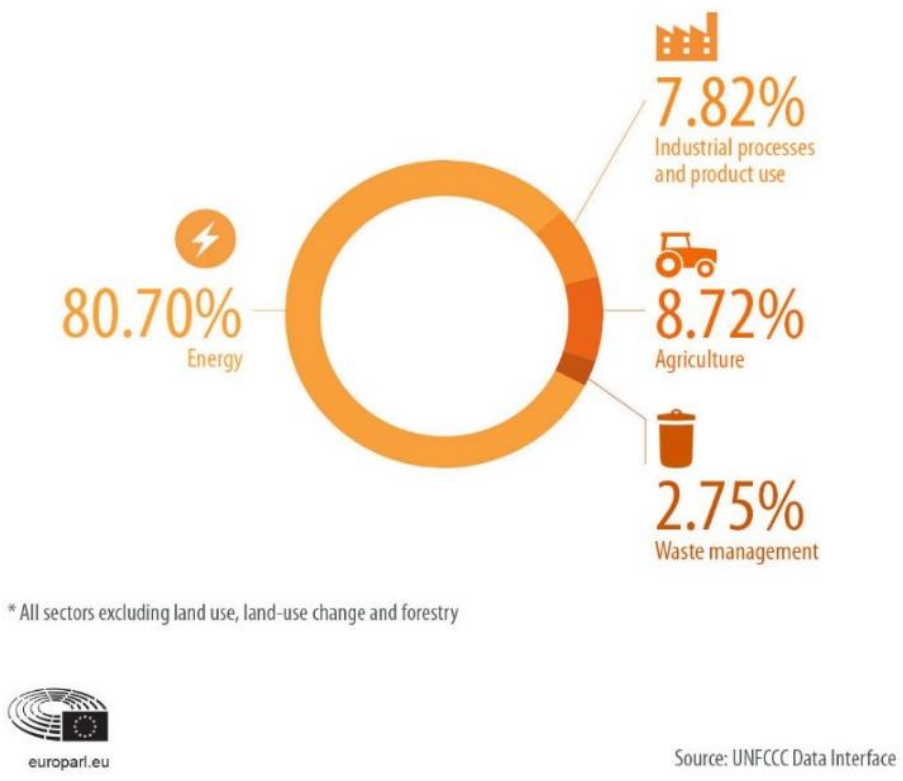

Figure. 3 Greenhouse gas emissions in the EU by sector in 2017

The climatic changes faced by large commercial agricultural holdings being different from those of subsistence, of very small dimensions. Climate change is expected to affect farmers in the south and south-east region of Romania in general and individually. Given that large farms usually have very specialized production, such as cereals and oilseeds, they are particularly vulnerable to the impact of frequent and long-term droughts, which affect their production and profit. But they are well-informed professionals, have the necessary technical and financial resources and have more options to adapt their agricultural systems to climate change through new technologies and irrigation systems. Smallholder farms, which practice subsistence farming, are very socially and economically vulnerable to adverse climatic events, in agriculture working directly about one third of the population. In some individual cases, farmers are specialized in the production of specific crops, such as onions or potatoes, thus increasing their level of vulnerability. In other cases, some intrinsic resistance can be found in smallholder communities due to the practice of organic farming and resource recycling, low carbon 
economy, diversity of production, strong social relations and (in some regions) alternative sources of income.

Agricultural production has a positive impact on the environment, but there are other determinants that lead to soil degradation and GHG. The level of GHG emissions from agriculture has decreased by over $20 \%$ since 1990, reaching $12 \%$ of the total GHG emissions at EU level in 2016, due to the reduction of nitrogen oxide emissions from the management of agricultural soils (mainly the reduction of fertilizer use). and the reduction of enteric fermentation emissions as a result of the overall reduction of livestock.

\section{Method}

The achievement of the objectives set in this doctoral research project requires the definition, construction and application of a specific research methodology focused on the evaluation of the costs and the economic-financial impact of the sequestration of $4 \%$ / year of the carbon dioxide at the farm level. The use of specific econometric instruments and methods is envisaged, highlighting the possibility of defining economic models for decarbonising agricultural production. From a methodological point of view, both descriptive analysis will be applied to highlight the factual situation of sequestration of a certain percentage of carbon dioxide at the farm level, as well as the interactive method to identify the possible trends, evolutions and perspectives in applying these measures. It will also adapt, calibrate and run in the subsidiary, some models already validated in the literature, which may complement the research, highlighting the role of nitrates in soil, fertilizers and the contribution of nitrogen from organic sources. emission of greenhouse gases in agriculture.

Studying the evolution of policies on decarbonisation of agriculture in contemporary economies. Evaluation of carbon storage and land use strategies in functional and competitive market economies.

The researches that will be carried out within this theme will focus on the description of factors through which to exploit the decarbonisation potential of agriculture and to promote an environmentally responsible agricultural model. At the same time, it is envisaged to improve the studies regarding the interactions determined by promoting the carbon dioxide storage at the farm level and the environmental requirements at the farm level, while analyzing the soil quality.

In the agricultural field a main objective of the development of the rural area is to maintain a low level of greenhouse gas emissions generated by the agricultural sector depending on the local characteristics. It is a priority for farmers to keep the soil covered, to use techniques for managing the environment of the land, for example, local agricultural production helps to maintain carbon in the soil.

As a rule, carbon stocks in agricultural soils can be increased by adapting certain agricultural activities. The research analyzes the fact that the carbon absorbers are as important as the emission reduction, being in close interdependence. Thus, a thorough knowledge of the quality of the soil with the maintenance and further improvement of the natural absorbents existing in the soils of agricultural lands may be essential. The analysis addresses the adaptation of fertilization mainly depending on the quality and texture of acid, neuter or alkaline soils. The importance of biologically fixed nitrogen $(\mathrm{Nb})$ is not revealed based on a predetermined study but by the method of case study by appreciation, thus the amount of nitrogen fixed biologically in the soil, mainly, following the symbiosis between Rhisobium and leguminous plants, depends very much on the species. cultivated, by the production and biomass incorporated in the soil, reaching up to hundreds of $\mathrm{kg} \mathrm{N} /$ ha.

The amount of nitrogen from the previous crops $(\mathrm{Nr})$ assimilably provided by the residues of the previous crop depends on the quantity and its composition depending on the nitrogen content and on the degree of lignification. It also depends on how well they were incorporated into the soil, the time when it was made, and the time elapsed since incorporation.

Loss of nitrogen in the form of gases in the atmosphere $(\mathrm{Ng})$ can occur through various mechanisms, in particular by denitrification and by volatilization of ammonia on the surface of alkaline soils. 
Thoth Publishing House

In the calculation method regarding the nitrogen inputs from organic sources will be considered the studies that determines the type or types of soil within the farm, as well as the main ones morphological and physico-chemical properties relevant to providing a maximum fertilization efficiencies and to reduce the risk of pollution with nitrates (and possibly phosphorus) of groundwater (slope, texture and soil permeability, degree of saturation in bases). Based on this information correlated with those resulting from agrochemical mapping, the level of soil fertility, the need for possible improvement measures and can be established the most suitable cultivation technologies regarding soil works, date sowing, methods of applying organic and mineral fertilizers and so on. The specific nutrient consumption for each crop is quantified in the form of regression equations specific to culture, established in fields long - term experimental ones, on the basis of which exports of nutrients for each crop, relative to the surface unit.

Prioritizing ensuring the conservation of carbon reservoirs, which are still present in the soil, leads to the need to orientate agriculture towards more environmentally responsible practices and why not to designate areas vulnerable to nitrate pollution from agricultural sources. Establishing the nutrition regime of the plants is a prerogative from the perspective of evaluating the doses of fertilizers to ensure an optimal nutrition, growth and development of cultivated plants.

\subsection{Studying the evolution of policies on decarbonisation of agriculture}

Evaluation of carbon storage and land use strategies in functional and competitive market economies.

The researches that will be carried out within this theme will focus on the description of factors through which to exploit the decarbonisation potential of agriculture and to promote an environmentally responsible agricultural model. At the same time, it is envisaged to improve the studies regarding the interactions determined by promoting the carbon dioxide storage at the farm level and the environmental requirements at the farm level, while analyzing the soil quality.

Table 1. Impact indicators

\begin{tabular}{|l|c|c|c|}
\hline \multicolumn{1}{|c|}{ Terminology } & Reference year & Reference year & Reference year \\
\hline \multicolumn{1}{|c|}{ Indicators } & 2012 & 2020 & 2030 \\
\hline The level of emissions from agriculture & $18299 \mathrm{Gg} \mathrm{CO} 2$ & $29882 *$ & $20.000 \mathrm{GgCO} 2$. \\
\hline $\begin{array}{l}\text { The weight of the functional surface from } \\
\text { the viable surface and the economically } \\
\text { viable margin for irrigation }\end{array}$ & $50 \%$. & $70 \%$ & $\begin{array}{c}90 \% \text { of the total } \\
\text { viable } \\
\text { infrastructure }\end{array}$ \\
\hline
\end{tabular}

Source MMAP and * Study "Elaboration of the elements of the report on the forecast progress, report under Article 3.2 of Decision 280/2004 / EC"

The EU has set targets to reduce its greenhouse gas (GHG) emissions by at least $40 \%$ by 2030 , compared to 1990. It is estimated that by 2030 they will be $30 \%$ below the 1990 level. (based on the Member State forecasts for March 2017).It is expected that in the medium and long term climate change will increasingly affect the agricultural sector, the constant increase in annual temperature, according to projections for Europe, varies between 0.5 degrees $C$ and 1.5 degrees $C$ by 2029 depending on from the global scenario.

Agriculture generates $14 \%$ of Romania's total GHG emissions in 2010, while the regional average, as well as the EU -15 and EU-27, was 10\% Managing forests to combat climate change Protecting, restoring and promoting the sustainable use of terrestrial ecosystems, sustainable forest management, combating desertification, stopping and repairing soil degradation and stopping biodiversity loss . 
The land management for carbon sequestration is highlighted by soil carbon inventory, especially by the form in which it is kept, the capacity, the persistence and bulk density, the textural class of the soil.

Changes in crop management practices that affect soil organic dynamics $\mathrm{C}$ are crop selection, high biomass crop rotation, crop residue management, nutrients and water management, use of organic fertilizers and management of organic soils and degraded land (Hutchinson et al., 2007; Petersen et al., 2013; Smith et al., 2012).

The research revealed a difference in soil carbon when the $\mathrm{C}$ factors had the effect of applying a management method based on the interdependence between production and crop rotation, soil quality, carbon uptake, climate. At the same time, soil carbon changes are caused by land use changes.

The best-performing prediction was obtained for the $\mathrm{C}: \mathrm{N}$ ratio $(\mathrm{R} 2=0.91)$, followed by phosphorus and potassium $(\mathrm{R} 2=0.75)$.

Predicting the performance of the remaining chemical properties in terms of $\mathrm{R} 2$ is greater than 0.60 , except for CEC $(\mathrm{R} 2=0.35)$.

$\mathrm{pH}$ (measured in $\mathrm{H} 2 \mathrm{O}$ )

$\mathrm{pH}$ (in $0.01 \mathrm{M} \mathrm{CaCl} 2$ solution)

Cation exchange capacity (CEC)

Calcium carbonates $(\mathrm{CaCO} 3)$

The global average concentration of atmospheric $\mathrm{CO} 2$ shows a steady increase, and this trend, together with increases in other greenhouse gases (GHGs), such as $\mathrm{N} 2 \mathrm{O}$ and $\mathrm{CH} 4$, is contributing to climate change, which is considered a major problem (Hartmann). et al., 2013; Petersen et al., 2013).

Globally, soil carbon sequestration could offset GHG emissions of 0.4 , which is equivalent to $5 \%$ to $15 \%$ of global fossil fuel emissions crop residues management, nutrients and water management, use of organic fertilizers, and management of organic soils and degraded land (Hutchinson et al., 2007; Petersen et al., 2013; Smith et al., 2012).

The management applied through the modification of some practices of crop management have first and foremost an impact on the organic texture of the soil through the rotation and selection of crops, which can produce biomass by managing crop residues.

Through nutrient and water management, the use of organic fertilizers and the management of organic soils and degraded land as studies have shown (Hutchinson et al., 2007; Petersen et al., 2013; Smith et al., 2012).

\subsection{The impact of climate change from the perspective of reducing greenhouse gas emissions.}

The climate characterized by successions of drought years followed by rainy years leads to, during the drought years, the accumulation of nitrates in the unsaturated area between the root layer and the groundwater aquifer, nitrates which are then transferred to the free water in the rainy years (piston effect). In this way, the annual losses of nitrates, even if they are small in the dry years, can lead, by accumulation, to great pollution of the groundwater aquifer in the years with excess precipitation.

\subsubsection{Agricultural practice}

It is considered as a good agricultural practice to adapt the fertilization and the timing of its fertilization to the type of agricultural crop and to the characteristics of the soil. The assessment of the nutrient requirement is made according to the nutrient reserve of the soil, the local climatic conditions, as well as the quantity and quality of the predicted production.

The hypothesis of carbon storage in the soil could be an option to mitigate climate change for agriculture, by managing the land and changing its use. To estimate all greenhouse gas exchanges.

In this study, we will consider the possibility of adapting the methods used to estimate carbon changes in the soil. For large-scale assessment, the schedule $\mathrm{CO} 2$ emissions from the soil should be taken into account. 
The land management for carbon sequestration is highlighted by soil carbon inventory, especially by the form in which it is kept, the capacity, the persistence and bulk density, the textural class of the soil. In certain areas, especially on soils with thin limestone substrate, there is an imminent danger of groundwater pollution. Depending on the local specificity, this danger should always be taken into account when applying organic fertilizers in such high risk areas.

Any nitrogenous fertilizer in organic form is mineralized as a result of the activity of bacteria present in the soil, ultimately resulting in nitric and ammoniacal nitrogen.

The main evolution factor towards mineral forms of nitrogen is the ratio between carbon and nitrogen in fertilizer $(\mathrm{C} / \mathrm{N})$. It may be more or less high and conditions the rate of mineralization. The transition from the organic to the mineral (ammoniacal or nitric) form depends on the value of the $\mathrm{C} / \mathrm{N}$ ratio.

It is estimated that in a normal soil 10-15\% of nitric nitrogen can be denitrified from the one produced annually by mineralizing the organic matter from the soil and from the one incorporated in the form of chemical fertilizers. These losses may be higher in soils with defective drainage, where the frequency and intensity of the phenomenon are higher.

It is difficult to estimate with minimum rigor what quantities of nitrogen or other nutrients from the previous crops can be taken into account in calculating fertilizer doses.

In general, it is possible to estimate quantities of 5-10 $\mathrm{kg}$ of $\mathrm{N}$ per year, higher in situations with intensive industrial activities in the area.

Nitrate losses in the form of nitrates, with surface runoff and percolation water, are the main diffuse pollutant of the aquatic environment, arising from agricultural activities.

The nitrogen in the soil is found, almost entirely, in the organic matter, and only a small fraction of it is in an immediately assimilable form for plants.

\subsubsection{The calculation method regarding the contribution of nitrogen from organic sources}

The calculation method regarding the contribution of nitrogen from organic sources is important for the assessment of greenhouse gas emissions from agricultural activities.

The nitrogen in the soil is found, almost entirely, in the organic matter, and only a small fraction of it is in an immediately assimilable form for plants.

Organic nitrogen can be used by crops only after its passage into an inorganic form through mineralization or gradual decomposition of organic matter from the soil, first in ammoniacal nitrogen and then in nitric nitrogen.

Typically, soil organic matter is made up of fractions that differ by the value of the $\mathrm{C} / \mathrm{N}$ ratio (carbon: nitrogen).

When estimating the level of the planned (planned) crops, the climatic characteristics of the place (in particular the thermal regime and the precipitation, including their annual distribution) must be taken into consideration, considering that they are decisive in the dynamics of the fertilizing elements in the soil and in particular in mineralization of organic matter and in the movement of nutrients in the soil profile, under the rooting zone. Of strategic importance is the type of fertilizer, the age and the technique of applying fertilizers with $\mathrm{N}$, with the amount of nitric nitrogen resulting from mineralization of the organic matter from the soil and other organic residues incorporated into the soil as well as with the amount of nitrogen entering the soil on other ways.

It is undeniable that nitrate losses from the soil are more intense in the seasons with more abundant rainfall, when, as a rule, the soil is deprived of vegetation. Under the specific conditions of our country, after the annual crops, more or less quantities of mineral nitrogen from the previous fertilization remain (about $50 \%$ of the applied nitrogen remains unconsumed by the crops) and from the mineralization of the organic matter from the soil.

Mineralization is more intense in autumn, when favorable conditions of temperature and humidity are encountered and when there is also an increased risk of nitrate water pollution. 
In counteracting this phenomenon, crop rotation plays an essential role.

It is recommended to rotate with the main crop a crop with rapid growth, capable of harnessing the residual nitrogen and that in spring can be used as green fertilizer for spring-summer culture.

Table. 2 The level of nutrients according to crops

\begin{tabular}{|l|l|l|l|l|}
\hline Nr.crt. & Specification of crops & $\mathrm{N}$ & $\mathrm{P}_{2} \mathrm{O}_{5}$ & $\mathrm{~K}_{2} \mathrm{O}$ \\
\hline 1 & Autumn wheat straw 1: 1.3 & 26.5 & 13.7 & 16.4 \\
\hline 2. & grain rye straw 1: 1 & 27.5 & 10.8 & 22.3 \\
\hline 3. & grain oat straw 1: 1.5 & 28.5 & 11 & 31.2 \\
\hline 4. & Corn grains: strain 1: 1.6 & 27.5 & 12.5 & 16.5 \\
\hline 5. & Sugar beet roots: Leaves and parcels 1: 1 & 4.9 & 2.0 & 6.0 \\
\hline 6. & Pea berry berries: 1: 1.5 edges & 61.0 & 16.6 & 28.0 \\
\hline 7. & Soybean beans: 1: 1.5 rods & 70.0 & 22.5 & 34.0 \\
\hline 8. & natural grass grass fan & 24.0 & 5.6 & 18.0 \\
\hline 9. & Natural grassland grass & 6.5 & 1.4 & 4.5 \\
\hline 10. & Hemp stems & 10 & 8,5 & 17.5 \\
\hline
\end{tabular}

The table above shows that the soil with the richest culture in $\mathrm{N}$ is the one with soy, while other relatively more frequent crops are located in the middle area with $1 / 3$ of $\mathrm{N}$, so that for each one the method will be applied of the appropriate nutrient, as in estimating the level of the planned (planned) crops, the climatic characteristics of the place must also be taken into account, since they are decisive in the dynamics of the fertilizing elements in the soil and especially in the mineralization of the organic matter and in the movement of nutrients in the soil. soil profile, below the rooting area.

Soil carbon changes due to land use changes.

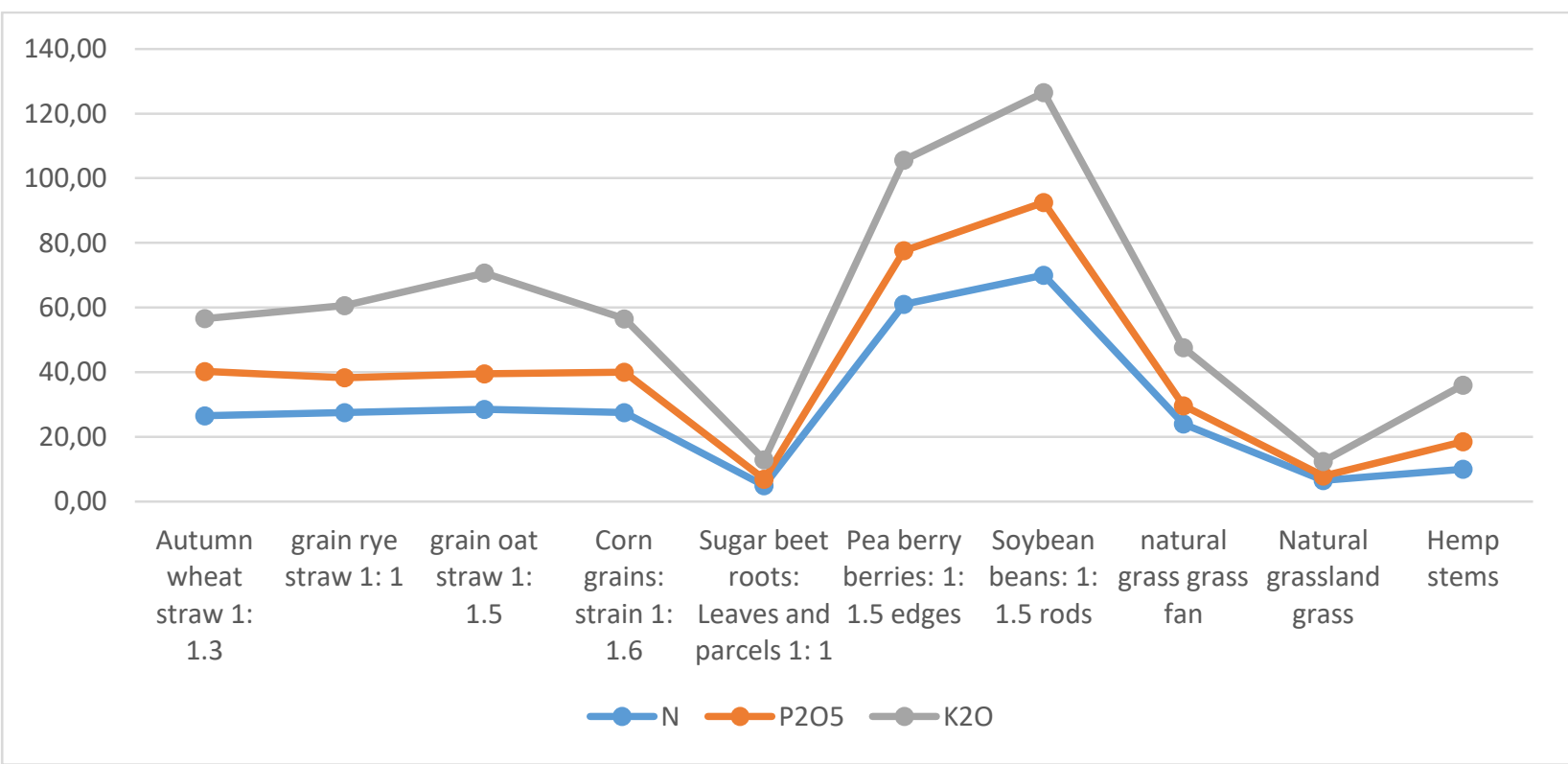

Nitrogen $(\mathrm{N}) *$

Figure:6 Specifications of crops

Phosphorus (P2O5)

Potassium (K2O) 
The maximum dose of nitrogen from organic fertilizers applied in the field may not exceed $170 \mathrm{Kg} /$ ha / year, and is in interdependence with the history of applying organic fertilizers on the land considered. Nitrogen needs vary considerably in different crops, and within the same crop, with the level of harvest possible to be achieved in a certain conjuncture of pedoclimatic and technological factors.

The production capacity of a crop, determined genetically, can be reached only under ideal conditions, when through the factors mentioned above optimal conditions for plant growth and development are achieved.

These corrections can be made using the following relationship:

$$
\mathrm{DN}=\mathrm{Nc}-(\mathrm{Ns}+\mathrm{Na}+\mathrm{Nb}+\mathrm{Nr})+(\mathrm{Ni}+\mathrm{Ng}+\mathrm{Nl})
$$

in which: DN is the nitrogen dose from fertilizer (organic + mineral) for the expected harvest, in $\mathrm{kg} / \mathrm{ha}$;

$\mathrm{Nc}$ is the nitrogen requirement for the expected harvest, in $\mathrm{kg} / \mathrm{ha}$;

Ns is the nitrogen available from the soil during the vegetation period, in $\mathrm{kg} / \mathrm{ha}$;

$\mathrm{Na}$ is nitrogen from irrigation water and from the atmosphere (powders, precipitation), in $\mathrm{kg} /$

ha;

$\mathrm{Nb}$ is nitrogen from biological fixation, in $\mathrm{kg} / \mathrm{ha}$;

There is no nitrogen from the mineralization of the plant residues of the previous crops, in $\mathrm{kg} / \mathrm{ha}$

$\mathrm{Ni}$ is nitrogen lost by immobilization by soil microorganisms, in $\mathrm{kg} / \mathrm{ha}$;

$\mathrm{Ng}$ is nitrogen lost through volatilization, including denitrification, in $\mathrm{kg} / \mathrm{ha}$;

$\mathrm{Nl}$ is nitrogen lost through surface runoff and leaching, in $\mathrm{kg} / \mathrm{ha}$.

Nitrate losses in the form of nitrates, with surface runoff and percolation water, are the main diffuse pollutant of the aquatic environment, arising from agricultural activities.

The nitrogen in the soil is found, almost entirely, in the organic matter, and only a small fraction of it is in an immediately assimilable form for plants.

The soil is a non-renewable resource that requires constant monitoring to prevent its degradation and to promote efficient management. The soil may degrade depending on many items. Of strategic importance is the type of fertilizer, the age and the technique of applying fertilizers with $\mathrm{N}$, with the amount of nitric nitrogen resulting from mineralization of the organic matter from the soil and other organic residues incorporated into the soil as well as with the amount of nitrogen entering the soil on other ways. Typically, soil organic matter is made up of fractions that differ by the value of the $\mathrm{C} / \mathrm{N}$ ratio (carbon: nitrogen).

The fraction, with the value of the $\mathrm{C} / \mathrm{N}$ ratio of order 8-11, called humus, is a stable fraction, which has reached equilibrium and therefore decomposes more slowly; other fractions with higher values of this ratio are decomposed faster than humus by soil microorganisms, whose activity is more or less intense, depending on the temperature and humidity conditions.

Solid fertilizers can produce pollution only in the case of heavy rains that occur immediately after application.

The prohibition periods for applying fertilizers on the ground are defined by the time interval when the average air temperature drops below $5^{0} \mathrm{C}$. This interval corresponds to the period when the requirements of the agricultural crop relative to the nutrients are reduced or when the risk of percolation / leakage to the surface is high. When using nitrogen fertilizers in a predominantly organic form, it must be borne in mind that nitrogen, before being absorbed by plants, must undergo mineral form through a series of transformations they undergo in the soil. Therefore, these fertilizers are applied with sufficient time before the time of maximum absorption by the crops.

Period of prohibition

Solid organic fertilizers Arable land and pastures November 1 - March 15

Arable land crops fall November 1 - March 1

Liquid organic fertilizers Other crops and mineral fertilizers 
Pastures October 1 - March 15

When applying chemical fertilizers it is necessary to take into account the crop specific requirements it is recommended to be applied according to the ratio between nutrients.

For example: those where $\mathrm{P} 2 \mathrm{O} 5$ predominates are more suitable for pre-sown grain cereals, those with a nitrogen ratio are suitable for technical crops, etc. Soil properties influence the use of fertilizers: larger quantities of fertilizers can be administered on heavy soils than on light ones; fertilizers with alkaline physiological reaction will be applied on acid soils, and fertilizers with acid physiological reaction will be applied on alkaline soils.

The periods when applying organic fertilizers should be determined according to different conditions:

- as early as possible, during the crop growth period, to maximize crop nutrient uptake and minimize the risk of pollution.

The application of fertilizers to meadows leads to the following positive effects:

- the increase of production, especially considering the fact that the fields with meadows generally have a lower quality class;

- distribution of production on the seams - on permanent pastures, especially on degraded pastures, after the first harvest, which in some cases exceeds $80 \%$ of the annual production, the plants harden what it does to obtain a small number of crops per year and weak quantitative.

On the heavily degraded meadows, only one crop is obtained during the year, and in the case of other meadows two or three harvests, but with the highest weight at the first harvest.

The application of organic fertilizers on permanent pastures (pastures and meadows) is subject to the condition of not exceeding the dose of $170 \mathrm{Kg} \mathrm{N}$ ha-1 year-1 and not being applied during the prohibition periods.

For the establishment of the fertilization plan, the export of the elements for each plot according to its mode of operation is considered. Thus, at a production of hay of $4 \mathrm{t} / \mathrm{ha}$, under the conditions of exploitation as hay, the export of: 80-85 Kg N, 25-32 Kg P2O5, 85-100 Kg K2O, 47-50 Kg CaO.

Member States may require the mention of calcium, magnesium, sodium and sulfur content fertilizers with secondary nutrients and, if the conditions provided for in Article 17 are met, from the fertilizers with main nutrients placed on their markets, shall be expressed as follows:

(a) in the form of oxide $(\mathrm{CaO}, \mathrm{MgO}, \mathrm{Na} 2 \mathrm{O}, \mathrm{SO} 3)$ or

(b) in elemental form $(\mathrm{Ca}, \mathrm{Mg}, \mathrm{Na}, \mathrm{S})$ or

(c) in both forms.

For the conversion of calcium oxide, magnesium oxide, sodium oxide and sulfuric anhydride content into calcium, magnesium, sodium and sulfur content, the following factors are used:

(a) calcium $(\mathrm{Ca})=$ calcium oxide $(\mathrm{CaO}) \times 0.715$;

(b) magnesium $(\mathrm{Mg})=$ magnesium oxide $(\mathrm{MgO}) \times 0.603$;

(c) $\operatorname{sodium}(\mathrm{Na})=$ sodium oxide $(\mathrm{Na} 2 \mathrm{O}) \times 0.742$;

(d) sulfur $(\mathrm{S})=$ sulfuric anhydride $(\mathrm{SO} 3) \times 0.400$.

The value withheld for the declaration is the value rounded to the nearest decimal place both when the content is expressed as oxides and if it is expressed in elementary form.

acid soils with $\mathrm{pH}<6.5$;

- neutral soils with $\mathrm{pH}=6.5$ - 7.5;

- alkaline soils with $\mathrm{pH}>7.5$.

Potentially accessible or mineralizable nitrogen comes from these less stable fractions. For soil conditions in Romania it represents between 1 and $2 \%$ of total nitrogen, both in soils.

Many studies have evaluated cropland, grassland and marshland, while Schmidt (2008) evaluated the transition from natural land to agricultural land. For example some studies the fact that a change factors from permanent cover to an annual harvest, plus simultaneous factors for the changes of the crop management involves the achievement of a balance between the soil carbon and its kinematic function of 
Thoth Publishing House

the use and degradation of the soil. Not infrequently the concern is to follow the cyclicality of the crops used depending on the texture of the soil. But a technical formula cannot be validated precisely because depending on the periods of maintenance of the soil with fertilizers these techniques have to be controlled according to external factors.

Consideration of soil properties, climate and crop management are vital characteristics from the perspective of emissions. The following scenarios are aimed at the interaction between crop growth, soil carbon, nitrogen needs and climate.

Most agricultural soils contain too little natural nitrogen available to meet the crop requirement during the growing period. As a result, it is necessary to supplement the nitrogen naturally contained in the soil each year. Applying the right amount of nitrogen at the right time is the basic requirement of good fertilizer management.

Each agricultural producer must understand the need for accurate assessment and periodic monitoring of plant nutrient requirements based on realistic forecasts, depending on:

- local technological conditions, tradition ;

- sun;

- climate;

- Expected production yield.

Results

Carbon sequencing is that storage function at the soil level, which highlighted the importance of determining soil quality and interdependence with the climate ecosystem. Soil is defined as a strategic carbon reservoir, which contains more carbon than is found in the atmosphere and in the terrestrial vegetation. These three carbon tanks are constantly changing. In many soils, soil organic matter, which contains about 55-60\% carbon by mass, comprises most or all of the carbon stocks current knowledge and knowledge gaps - about the role of soils in carbon, nitrogen and water cycles. The accumulation of stabilized carbon in the soil requires a control in terms of storage. The quantity and type of residues produced by plants are also influenced by the addition of fertilizers, which are indispensable for sustaining the productivity of plants in agricultural systems. In addition, by their effect on the microbial activity, the carbon contributions of the plants, the climatic factors, such as the temperature solution.

In order to reduce the negative effects of climate change on agriculture, risk management tools need to be implemented to limit the negative effects of natural disasters on agricultural production.Adapting to climate change is not just a challenge and a condition that, in the long term, new methods will be developed, planning new agricultural techniques more environmentally friendly to be applied by farmers in increasing numbers. Accounting for a concept of stepping up processes in the agri-environment field in order to prefigure the application of greener models in agriculture, while reducing the level of GHG, is not to be neglected.

The quality of the soil is determined by the texture of the soil that must be maintained through the agricultural practices, in order to manage a possible degradation due to the climate or the vegetation. The calcium carbonate content is strongly correlated with the quality influenced by the distribution of clay in soils, the geographical area as well as perhaps the most important of the material residues. Thus, it can be seen that the distribution of nitrogen in the soil is closely related to the organic carbon, vegetation and climate as well as the texture of the soil. Therefore, the use of land, the use of innovative agricultural practices based on a management designed on the basis of local data and adapted to agricultural production can be a factor in improving soil performance.

In our opinion, the agricultural lands in general and especially those in Romania have considerable potential for carbon capture and storage. It is vital to have improved agricultural systems that efficiently utilize nutrient resources, increasing not only the amount of carbon in the soil, but also the biodiversity and resistance of agriculture even to climate change. As a rule, carbon stocks in agricultural soils can be increased by adapting certain agricultural activities. Research also shows that carbon absorbers are just as 
important as reducing emissions. Maintaining and further improving the natural absorbents represented by soils, agricultural land and coastal wetlands are essential.

At the same time, the paper shows the vital role of green manure can be applied on any type of soil, but they have a higher efficiency on podzolic and sandy soils. The technique is aimed at the depth of incorporation which is between $18-25 \mathrm{~cm}$, depending on soil, humidity, volume of plant mass, etc. For ease of incorporation, the recommendation is when the crop is very rich and the stems are long. On heavy clay soils, as well as on sandy areas, it is recommended that the incorporation be done at least 30-45 days before the autumn sowing. However, in areas with sufficient rainfall, the incorporation is good to be done only 2-3 weeks before the autumn sowing. For spring sowing, this type of fertilizer is particularly suitable, provided that its burial is done in the fall at the latest. It is good to take into account, when determining the time of incorporation and the recommendations regarding the optimum stage of vegetation of the crop used as green fertilizer. It is estimated that in a normal soil $10-15 \%$ of nitric nitrogen can be denitrified from the one produced annually by mineralizing the organic matter from the soil and from the one incorporated in the form of chemical fertilizers. These losses may be higher in soils with defective drainage, where the frequency and intensity of the phenomenon are higher.

\section{Conclusions}

Whether agriculture can contribute to reducing greenhouse gas emissions remains a question. That is why scientific research has shown that by achieving a successful management, adaptable solutions can be identified in practice on areas of interest, depending on the quality of the soil from the geographical environment. It is known that research and innovation activities and consultancy services can help farmers to adopt production systems that best meet local characteristics. Regarding land use changes and land management, research has revealed that there are uncertainties in the levels of carbon stock changes due to variations in local conditions and lack of reliable land data (Borjesson and Tufvesson, 2011). It is also a constant concern and concern of the research regarding the fact that at present, there is nothing common in the standard procedure for the able of carbon in soil (Arzoumanidis et al., 2014; Brand ao et al., 2013; Petersen and et al., 2013). The role of research in the field and studies have shown an important factor in the fact that a reduction of the carbon footprint per ton of food produced from organic farming compared to conventional agriculture, in principle, due to the abandonment of the use of chemical fertilizers and pesticides. One of the main objectives in the field of agriculture is to maintain a low level of greenhouse gas emissions generated by the agricultural sector. Farmers must continually improve the techniques adapted to the new challenges of keeping the soil covered, to use techniques for managing the environment of the land to help maintain the carbon in the soil.

Without the foreseeable future forecast in climate change, the statement "if we want the natural environment to contribute to reducing greenhouse gas emissions, we must learn to manage methane and nitrogen oxide emissions from agriculture differently," he explains. Detlef Schmulze, from the Max Planck Institute in Iena (Germany).

In conclusion, we can say that, conservation and improvement of the state of natural resources and habitats by encouraging the use of innovative, environmentally friendly agricultural production methods that come to protect the environment, biodiversity conservation and the improvement of water, soil and natural landscape quality are vital. In the field of rural development, agri-food economy, economic environment, we need a clean environment that is based on the rational use of natural resources, increasing competitiveness by identifying the best practices in the field.

In part, the need for innovation in agriculture will contribute to the understanding of the economicfinancial impact of the storage of a percentage of carbon dioxide at the farm level and to the definition of the demands imposed by achieving a functional and highly competitive market economy. The role of the research is also the possibility of developing environmentally responsible agricultural production models that will significantly contribute to the decarbonisation of agriculture. 


\section{References}

[1] Andrei, T., Bourbonnais, R. (2008): Econometrics, Bucharest, Economic Publishing House, p. 111123;

[2] Andrei, T., Stancu, S., James, AI, et al. (2008): Introduction to econometrics using Eviews, Bucharest, Economic Publishing House, pp. 66-82;

[3] Communication from the Commission Europe 2020 A strategy for smart, Sustainable and inclusive growth, Brussels, 3.3.2010 COM (2010) 2020 Available at: http://europa.eu/press_room / pdf /

[4] Directive 96 / 61 / EC, dated September 24, 1996 concerning the integrated prevention and control of pollution. Available at www.eur-lex.europa.eu. $\mathrm{S} \backslash$;

[5] Comănescu, M., 2010: Increasing environmental responsibility, Bucharest, Journal of Theoretical and Applied Economics, Volume XVII (2010), No. 5 (546), pp. 39-52

[6] Duţu, M. (2008). Urban planning law, Ed. Univers Law, Bucharest

[7] E Views, User Guide, Version 7.0 QMS Quantitative Micro Software, Irvine, California, pp.140$141,2010$.

[8] Lucarelli Sonia and Ian Manners (2006): Values and Principles in EU, Routledge 2 Park Square, Milton Park, Abingdon, Oxon;

[9] Romania's National Strategy for Sustainable Development 2013-2020-2030 Available; www.anpm.ro (EC) Regulation no. 614/2007, dated May 232007 concerning the Financial Instrument for the Environment. Available at: www.eur-lex.europa.eu;

[10] Scheuer, Stefan (2005): EU Environmental Policy Handbook. A Critical Analysis of EU Environmental Legislation. Making it accessible to environmentalists and decision makers, Brussels: European Environmental Bureau;

[11] Wallace, Helen, William Wallace \& Mark Pollack (2005) Policymaking in the European Union, Publisher European Institute of Romania, Bucharest;

[12] https: //www.mae.ro/sites/default/files/file/Europa2021/Strategia_Europa_2020.pdf; 13. European Commission (2015) Nature and biodiversity newsletter, 2015,Number 37, January;

[13] http://www.ier.ro/sites/default/files/pdf/politica_de_mediu_brosura_nr.4_.pdf;

[14] http: //mmediu.ro/new/? PAGE_ID = 81;

[15] Report on the implementation of environmental policies - Romania-EU, Brussels, 2017

[16] European Commission Flash Eurobarometer 426 2015. "SMEs, resource efficiency and green markets) https://data.europa.eu/euodp/en/data/dataset/S2088_426_ENG

[17] European Commission, 2015. Tax reforms in EU Member States - in 2015, 008 institutional document 008 dated September 2015, p. 68.

[18] www.insse.ro

[19] http: //ec.europa.eu/eurostat/data/database

[20] Adewale, C., Reganold, J. P., Higgins, S., Evans, R. D., \& Carpenter-Boggs, L. (2019). Agricultural carbon footprint is farm specific: Case study of two organic farms. Journal of Cleaner Production, 229, 795-805.

[21] Andrei, J. V., Dusmanescu, D., \& Mieila, M. (2015). The influences of the cultural models on agricultural production structures in Romania and some EU-28 countries-a perspective. Economics of Agriculture, 62(297-2016-3679), 293-307.

[22] Aznar-Sánchez, J. A., Piquer-Rodríguez, M., Velasco-Muñoz, J. F., \& Manzano-Agugliaro, F. (2019). Worldwide research trends on sustainable land use in agriculture. Land Use Policy, 87, 104069. 
Thoth Publishing House

[23] .CES.(2008). Avizul Ccomitetului Economic şi Social European privind relaţia dintre schimbările climatice şi agricultură în Europa, NAT/384 Schimbările climatice şi agricultura în Europa Comitetul Economic şi Social European, Bruxelles, 9 iulie 2008.

[24] Huang, J., Chen, Y., Pan, J., Liu, W., Yang, G., Xiao, X., ... \& Zhou, L. (2019). Carbon footprint of different agricultural systems in China estimated by different evaluation metrics. Journal of Cleaner Production, 225, 939-948

[25] Ramírez, P. B., Calderón, F. J., Fonte, S. J., \& Bonilla, C. A. (2019). Environmental controls and long-term changes on carbon stocks under agricultural lands. Soil and Tillage Research, 186, 310 321.

[26] .Westhoek, H., Van Zeijts, H., Witmer, M., Van den Berg, M., Overmars, K., Van der Esch, S., \& Van der Bilt, W. (2014). Greening the CAP. An analysis of the effects of the European Commission's proposals for the Common Agricultural Policy,2020.

[27] Yadav, D., \& Wang, J. (2017). Modelling carbon dioxide emissions from agricultural soils in Canada. Environmental pollution, 230, 1040-1049.

[28] Zhang, N., Zhang, G., \& Li, Y. (2017). Does major agriculture production zone have higher carbon efficiency and abatement cost under climate change mitigation. Ecological Indicators.

[29] Agovino, M., Casaccia, M., Ciommi, M., Ferrara, M., \& Marchesano, K. (2019). Agriculture, climate change and sustainability: The case of EU-28. Ecological Indicators, 105, 525-543.

[30] https://www.europarl.europa.eu/news/ro/headlines/priorities/schimbarileclimatice/20180706STO07407/progresul-ue-catre-atingerea-obiectivelor-in-domeniul-schimbarilor -climatice,

[31] http://unfccc.int/national_reports/annex_i_ghg_inventories/national_inventories_submissions/items /8108.php.

[32] The data provided have been prepared for use by internal research activities in the Joint Research Center (JRC, Ispra) in the context of developing land ownership maps for the GlobalSoilMap.net project and the FP7 RECARE program (Grant No. 603498). The data were prepared for research purposes by the JRC (European Commission)

[33] Council Directive 91/676 / EEC of 12 December 1991 on water protection against pollution with nitrates from agricultural sources - "Nitrates Directive" - 